\title{
Understanding the fall-related safety issues in concrete formwork
}

\author{
Vigneshkumar Chellappa*, and Urmi Ravindra Salve \\ Department of Design, Indian Institute of Technology Guwahati, Guwahati, India - 781039
}

\begin{abstract}
The construction industry recorded high rates of fatalities and injuries due to falls at the workplace. Among other activities, concrete formwork tends to have more fatal falls. This study aims to understand the fall-related safety issues in the formwork lifecycle of construction projects. To achieve this, the process of formwork activities was mapped, and the safety risks associated with each activity were classified. Method development and risk identification focused on interviews with construction professionals involved in the construction of formwork and site observations of the formwork activities. The overall finding was that pouring, stripping, and erection activities have more issues related to falls. Future research is being carried out to assess the risks of falls from the construction experts' views to prevent fall accidents in the future.
\end{abstract}

\section{Introduction}

Formwork has been used widely on construction projects as a temporary structure. Formwork is essentially a mould for concrete that can be shaped into desired shapes and dimensions. Formwork can either be integrated as a permanent part of the design or removed after the concrete's desired strength has been achieved. Formwork can account for up to $60 \%$ of the concrete structure's total cost [1]. Depending on the function and the area of use, there are many types of formwork available on the market, including engineered formwork systems and site-built timber formwork [2].

Temporary platforms and working at height are frequently involved during the formwork use, influencing the workers' safety in construction projects $[3,4]$. Furthermore, workers are at certain fall risks when they are associated with formwork assembling and stripping. Both safety and productivity of the worker are affected by the place of activity [5].

Formwork activities are associated with a high level of injuries and accidents across all construction tasks [6-13]. The riskiest phase concerning falls was preparing formwork for concrete structures [14-16]. Of all the fatal incidents caused by falls in China in1999, a total of 34 incidents were reported as having occurred during formwork preparation of concrete structure, accounting for $6 \%$ of all deaths related to falls [17]. Huang and Hinze [18] found out that when temporary systems are used, the possibility of falling is always present.

*Corresponding author: vigneshkumarchellappa@gmail.com 
Based on the OSHA database, recently, Kang et al. [19] investigated fall accidents from 1997 to 2012 and found that concrete formwork accounts for $2 \%$ of fatal falls in the U.S.

Although there have been many studies related to fall accidents in construction, no research has to date assessed the fall-related safety issues associated with formwork activities; also, up to the authors' knowledge, studies that relates construction safetyconcrete formwork-fall accidents are not carried out in India. Therefore, this study aimed to understand safety issues related to fall in construction projects' formwork cycle to explore possible approaches to fall accidents. Form this study, safety and health experts, practitioners, professionals, and all construction partners in India and worldwide are intended to benefit, which connects accident monitoring results to accident prevention systems.

\subsection{Knowledge and practice of formwork}

Materials of formwork are typically shaped and mounted into frames, and the frames are then installed in the correct position and orientation. The formwork materials could still be used for a further concrete pour after the concrete is poured and healed, and the formwork extracted. As part of this process, several work assignments are needed. The construction of formwork is a standard process, but only minimal studies accessible that address the particular tasks involved in the construction process. Hurd [1] explains and determines formwork construction operations implicitly. According to Hallowell [20] and Amrutha et al. [3], the main categories based on formwork activities are Assembly, Erection, Forming, Pouring concrete, Transportation, and Stripping. In research concerning formwork workers' safety, only limited studies were found in which the authors performed an analysis on quantifying workers' safety risk in the U.S $[5,19]$ and Spain [6] for specific tasks.

\section{Research objectives and Method}

The research study's objectives were to map the workflow for the typical process of formwork construction and understand the fall-related safety issues associated with each stage. The following research questions have been identified to direct the study:

1. What are the steps involved in the formwork construction?

2. What are the fall-related safety issues that commonly affect workers working-atheight during each activity?

This study adopted a mixed-methods approach that includes targeted interviews and site observations to address these research questions (1) a formwork questionnaire to be responded through an interview method, and (ii) on-site observation to understand and ensure the formwork activities. A questionnaire was created based on Amrutha et al. [5]'s questions for interviewing construction experts to describe the different tasks related to the formwork lifecycle in-depth and understand fall-related safety issues. This survey aimed to collect details and record observations about the formwork activities. In total, 12 responses from participants employed on four construction projects in Chennai and Bangalore were collected. The participants included senior engineers, foremen, and site engineers. The researchers prepared an interview form with numerous choices to aid the researchers to conduct formal interviews and ensure consistency between interviews. The interview questions were asked in following topics:

- The formwork construction steps (e.g., materials preparation, formwork panels' assembly, formwork erection, transportation, and stripping of formwork)

- Fall-related safety issues that are commonly found in formwork.

Two projects using conventional plywood vertical formwork were identified for on-site observation. Both the projects were in the same area to ensure the study team's consistent 
proximity to the site during the concrete activities. To reduce variability by maintaining consistency in general use conditions, observations were limited to vertical formwork (i.e., wall and column formwork) at every project site. Together with the site observations, the interview responses were documented for study. Later, the construction formwork lifecycle was mapped by merging these data using value stream mapping. The common activities of construction traders were also established for each phase of the formwork lifecycle.

\section{Results and discussion}

\subsection{Mapped workflow for common formwork use}

A workflow was mapped (see Fig 1), based on the 12 responses and formwork operations observed on different projects. By removing the procedures not done at the specific project location, the mapped workflow acquired for common formwork use can be modified to suit the formwork use on any project.

The following steps are one common formwork cycle use:

1. Stockpile - When multiple forming materials are shipped to a construction site, they are stacked elsewhere by storing them as per size, specific material, or other appropriate requirements. On-site storage is usually done outdoors and is kept uncovered.

2. Move (optional) - Sheets are shifted to cut into the desired shape.

3. Carpenters yard/prepare - The components are taken to a specified work area in this phase and cut to the dimensions needed to create formwork as per project requirements.

4. Move (optional) - For the installation at a later date, the ready components may or may not be transferred elsewhere.

5. Site place - The components are kept at the workplace for fixing.

6. Assemble - Using different connectors, such as clamps, bolts, and nails, the prepared parts are made into formwork panels, powered by hand or other mechanical means.

7. Erect - For column or wall, the mounted formwork panels are lifted by crane, hand (handset), or other means and kept in place around the reinforcing bars. The other side of the formwork is placed next to the wall forming, and using ties, the two panels are joined. The panels on two sides are positioned for columns, and clamps, bands, or other means of connection are used to attach the forms. Stakes, braces, and any other false support work needed are also put in.

8. Pour - Concrete is pumped and vibrated to consolidate the concrete externally or internally.

9. Strip - The stripping is the process of removing the forms from the concrete. It is possible to execute this procedure manually or by mechanical means, such as cranes or forklifts.

10. Cure - The concrete is left to reach design strength under ambient temperature conditions.

11. Visual inspection - The formwork status is measured through visual inspection, and whether or not to use the formwork again is determined. If the decision is no, then the formwork panel is disposed of into scrap or installed in an alternative usage.

12. Move (optional) - This step is needed if the formwork needs to be transferred for cleaning to a different spot.

13. Clean/Dismantle - The formwork panels are cleaned and oiled from the remaining concrete and any other debris that may have collected. Additional defects present 
on the formwork can be identified after cleaning. The panels are removed for transportation and storage if the panels used on the specific project are over.

14. Re-use decision - The cleaned panels of formwork are visually rechecked to ensure that all components can deliver the required surface finish. If some parts are unacceptable, they are replaced and put in the scrap pile or for alternative purposes.

15. Move (optional) - In this step, the panels are relocated elsewhere due to limited space on the construction site.

16. Stockpile - The cleaned panels are kept aside before the next scheduled pour.

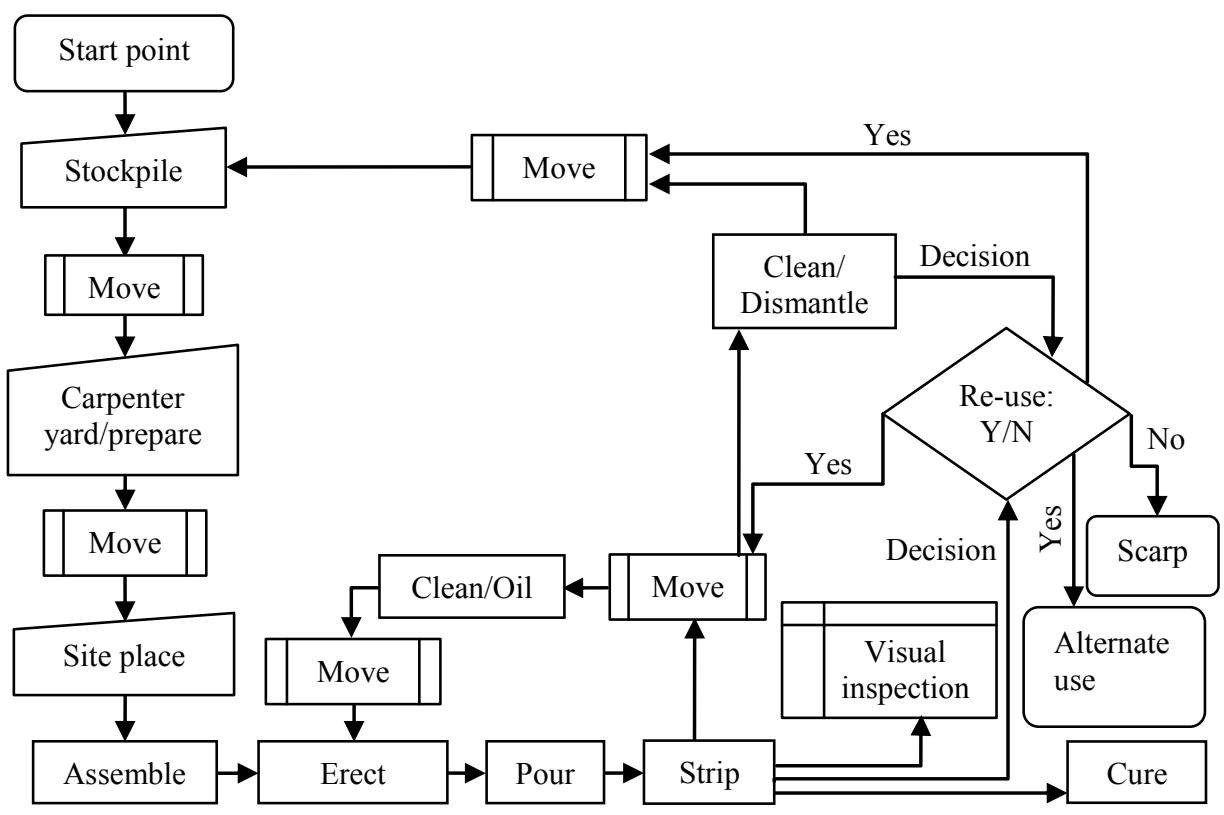

Fig. 1. Model of formwork construction method workflow.

Either alternative use or scrap is the endpoints of formwork components that are no longer suitable for formwork use. Scrapped items are stored in the waste container and are not used anywhere in the project. Those materials that are retained for alternative use may be modified as barriers, stairs, slabs, or other project specifications for use. It is to be noticed that it is not mandatory for all the steps described above to be present in any forming period. This common cycle can be tailored to suit any formwork type or any projects' formwork usage cycle by skipping the steps not taken on the individual project.

\subsection{Model validation}

The mapped formwork workflow was verified on two different projects through on-site monitoring. Mapped workflows developed for the plywood formwork monitored in each project. For these specific project workflows (illustrated below), each figure has various forming phases represented in it. 


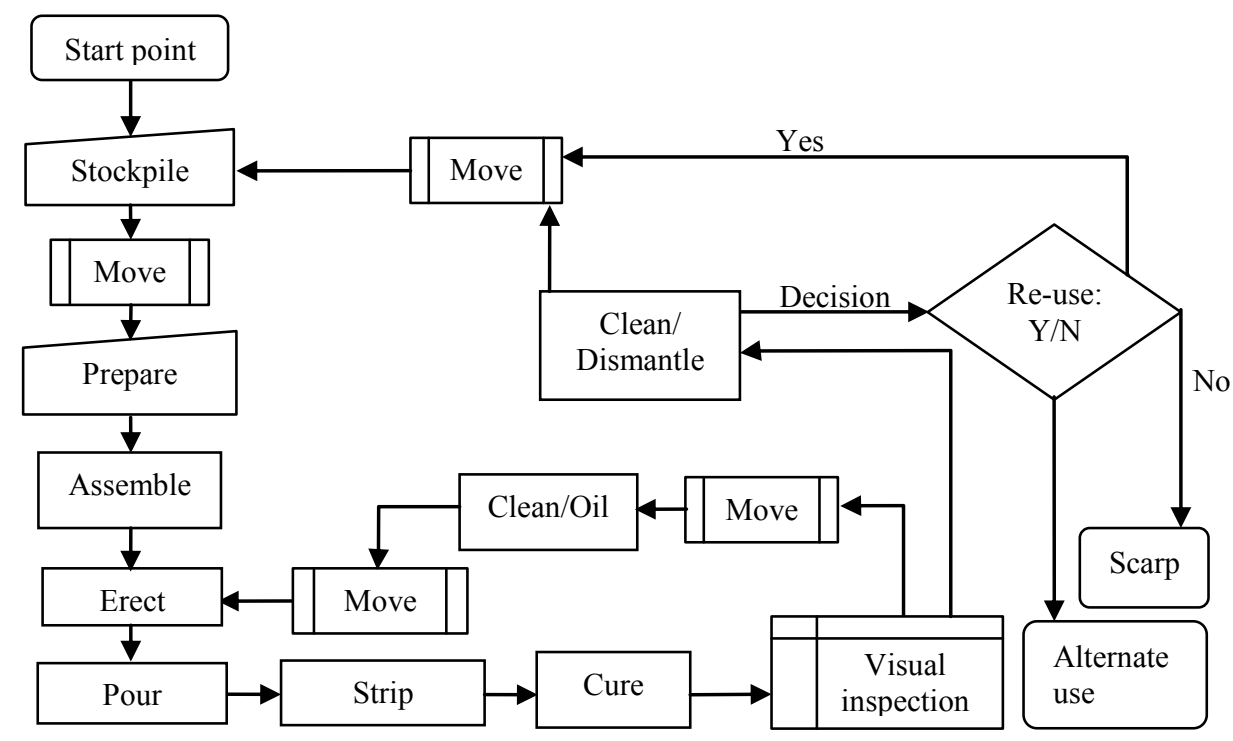

Fig. 2. Mapped workflow - Project 1 (Plywood - wall).

Figure 2 displays all the various stages of formwork found during the retaining wall of Project 1. Either of the paths can represent one forming cycle as set out in the direction of the arrows. For instance, visual review is conducted after erection, pouring, and stripping. If any portion of the forming panel needs replacement, the pieces will be removed, and the panel cleaned and oiled. Depending on the work progress and the next concrete pour expected time, the cleaned panel will be erected for subsequent use or stored elsewhere on the site. While in Figure 1, the mapped workflow shows a one formwork cycle for all possible steps, Figure 2 shows the various workflows observed in Project 1 and excludes the unnecessary steps.

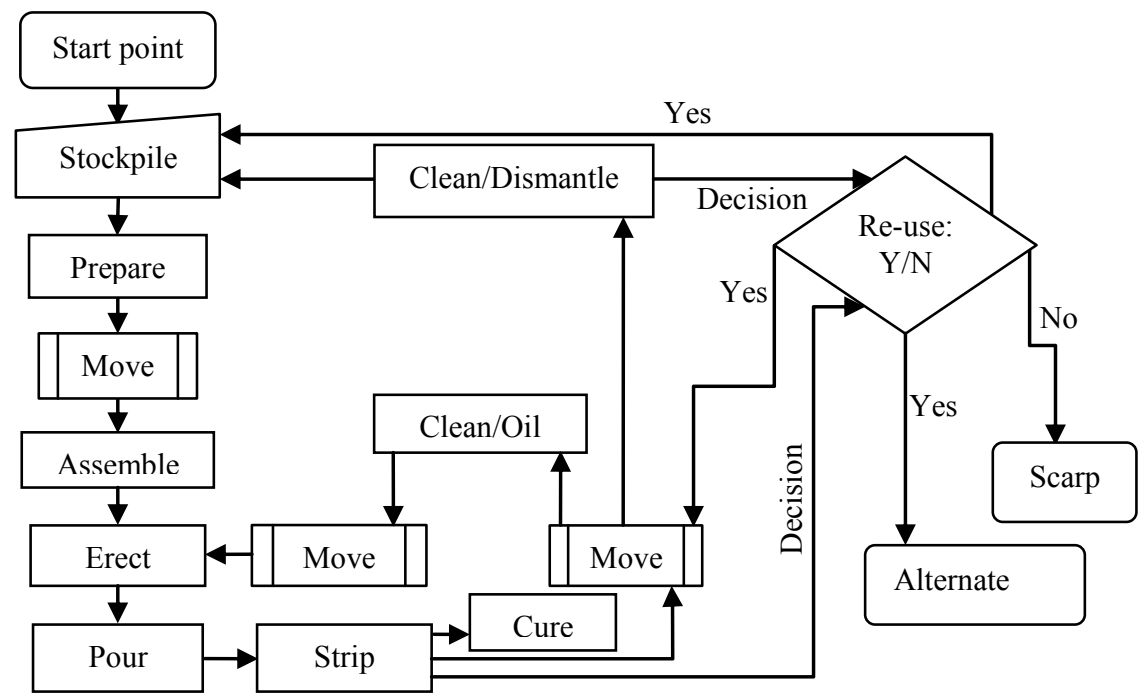

Fig. 3. Mapped workflow - Project 2 (Plywood - Column). 
The second project monitored was column formwork. When the pouring day was close, the stored components were assembled and erected. After the concrete was poured and cured, the column forms were stripped manually, and forms from columns with identical sizes were taken to the next place, cleaned and oiled, and erected. Two different forms of formwork have been found in this project, but the project workflow (Figure 3) indicates only the forming cycles encountered by the plywood forming. The other formwork types used on the project have not been considered for mapping the workflow.

\subsection{Safety issues related to fall in formwork activities}

The interviewee asked the participants an open-ended question about the fall-related safety issues while dealing with each formwork activities. In formwork use, there are totally 16 steps in the mapped workflow, in which 4 tasks were considered some amount of fall risks to workers. The most common answers received have been tabulated and can be found in Table 1. In Table 1, only few safety issues are listed for each activity.

Table 1. Fall-related safety issues in formwork activities

\begin{tabular}{|c|c|c|c|}
\hline $\begin{array}{l}\text { Activity } \\
\text { no }\end{array}$ & Activities & Activity description & Fall-related safety issues \\
\hline 1 & $\begin{array}{l}\text { Formwork } \\
\text { assembly }\end{array}$ & $\begin{array}{l}\text { With the use of components, brackets, } \\
\text { nail guns, etc., assembling formwork } \\
\text { panels. }\end{array}$ & - Workplace conditions \\
\hline 2 & $\begin{array}{l}\text { Formwork } \\
\text { panels } \\
\text { Erection }\end{array}$ & $\begin{array}{l}\text { Installing forms, shoring, snap ties, } \\
\text { stakes, rebar, and other items at a height } \\
\text { that required fall protection. }\end{array}$ & $\begin{array}{ll}- & \text { Struck-by-objects } \\
\text { - } & \text { Moving objects } \\
\text { - } & \text { Workplace conditions } \\
\end{array}$ \\
\hline 3 & $\begin{array}{l}\text { Concrete } \\
\text { pouring }\end{array}$ & $\begin{array}{l}\text { Pouring concrete, compacting it with } \\
\text { vibrator or manually, and allowing it to } \\
\text { cure, at a height that necessitates fall } \\
\text { protection }\end{array}$ & $\begin{array}{ll}\text { - } & \text { Repetitive work } \\
\text { - } & \text { Vibration } \\
\text { - } & \text { Moving objects } \\
\text { - } & \text { Falling objects } \\
\text { - } & \text { Workplace conditions } \\
\end{array}$ \\
\hline 4 & Stripping & $\begin{array}{l}\text { After the necessary curing time, remove } \\
\text { the forms and supporting falsework, from } \\
\text { a height requiring fall protection. }\end{array}$ & $\begin{array}{ll}\text { - } & \text { Struck-by-objects } \\
\text { - } & \text { Panels removal } \\
\text { - } & \text { Workplace conditions }\end{array}$ \\
\hline
\end{tabular}

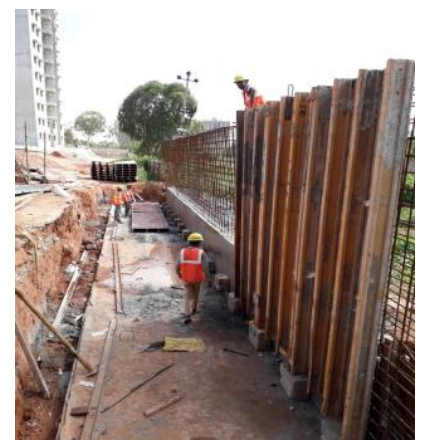

(a) Panel erection (wall)

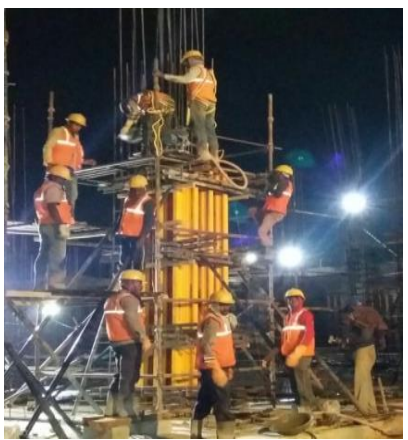

(b) Concrete pour (column)

Fig. 4. Examples of formwork activities of on-site observations.

Examples of observed activities are shown in Figure 4. Figure 4a shows a crew worker climbing up the formwork to erect the panels. Figure $4 \mathrm{~b}$ illustrates crew workers climbing 
up a working platform to pour concrete. It can be seen here harness were not used by some workers during ascending and descending activities.

\section{Conclusion}

The findings of this study are presented here. First, the formwork lifecycle was mapped by creating tasks that makeup one formwork use cycle, which was then confirmed by observing formwork use on two projects. Creating a mapped workflow of the formwork usage cycle resulted from obtaining a clear picture of the various formwork activities being used on construction sites. Stockpiling, moving, and arranging materials; positioning and erecting panels; pouring concrete; stripping; visual checking; cleaning; and removing/reusing were found to be part of the general site lifecycle of vertical concrete formwork. The workflow model concludes with the materials being scrapped or re-used in other ways when the formwork materials are no longer usable. But the workflow varies from project to project. Some steps may or may not be carried out on a project. The general mapped workflow can be extended to any project by modifying the workflow to remove any unnecessary steps if necessary. The second objective was to understand the fall-related safety issues associated with the use of formwork. In this stud, few fall-related safety issues were listed. Pouring has a large number of fall-related problems, followed by stripping and erection. Future research efforts are being carried out to identify and evaluate the fall risks that the workers are exposed to while carrying out formwork activities.

\section{References}

1. M. Hurd, Formwork for Concrete. Michigan: American Concrete Institute (2005).

2. A. Barbosa, J. Gambatese, A. Das, A.C. Pestana, A. C. (2014). Mapped workflow for safety and reliability assessments of use and re-use of formwork, in Proceedings of the Construction Research Congress, 19-21 May 2014, Atlanta, Georgia (pp. 1821-1830).

3. A.S. Hanna, Concrete formwork systems, CRC (1998).

4. Code of practice formwork, Safework NSW, Australia (2020)

5. D. Amrutha, A.R. Barbosa, J. Gambetese, Risk and reliability associated with use and reuse of vertical formwork, Thesis, Oregon State University (2014).

6. A. López-Arquillos, J.C. Rubio-Romero, A.G. Gibb, J. Gambatese, Safety risk assessment for vertical concrete formwork activities in civil engineering construction, Work, 89 (2013).

7. C.F. Shen, Formwork engineering: economic, design, assembly, and safety, Taipei: Shen Publisher, 8-15, (1996).

8. Chien-Ho. KO, Jiun-De. KUO, Making formwork construction lean, J. Civ. Eng. Manag, 21, 444-458 (2015).

9. M. Hallowell, J.A. Gambatese, Activity-based safety risk quantification for concrete formwork construction, J. Const. Eng. Manag, (2009).

10. S. Chi, K. Hampson, H. Biggs, Using BIM for smarter and safer scaffolding and formwork construction: a preliminary methodology, in proceedings of the CIB WO99 International Conference on Modelling and Building Health and Safety, 2012, Singapore, (pp. 64-73). 
11. J.A. Gambatese, A. Barbosa, A. Das, Use and re-use of formwork: safety risks and reliability assessment, The Centre for Construction Research and Training, Final report (2014).

12. A. Haduong, J.J. Kim, V. Balali, Statistical results on incidents for formwork safety in concrete structures, in the Proceedings of the Construction Research Congress, 2-4 April 2018, New Orleans, Louisiana.

13. J. Lee, J. Cho, An inference method of safety accidents of construction workers according to the risk factor reduction of the Bayesian network model in linear scheduling, Int. J. Manag, 11, 1-12, (2020).

14. P. Zambianchi, Solai in sicurezz, specializzata, 168, 742-749 (2007).

15. R. Arifuddin, R.U Latief, A. Suraji, An investigation of fall accident in a high-rise building project, IOP Conf. Series: Earth and Environmental Science, 419, 1-7 (2020).

16. Government of India (GOI), Report on modern formwork system (2017).

17. C.M. Tam, S.X. Zeng, Z.M. Deng, Identifying elements of poor construction safety in China, Saf. Sci, 42, 569-586 (2014).

18. X. Huang, J. Hinze, Analysis of construction worker fall accidents, J. Const. Eng. Manag, 129 (2003).

19. Y. Kang, S. Siddiqui, S.J. Suk, S. Chi, Trends of fall accidents in the U.S. Construction Industry, J. Const. Eng. Manag, 8 (2017).

20. M. Hallowell, A formal model for construction safety and health risk management, PhD Dissertation, Oregon State University (2008). 